\title{
SOLOS E PROCESSOS EROSIVOS NA GEOGRAFIA ESCOLAR BRASILEIRA
}

Soils and erosive processes in brazilian school geography

Solos y procesos erosivos en geografía escolar brasileña

\section{Junimar José Américo de Oliveira*1}

${ }^{1}$ Doutorando em Geografia pela Universidade do Estado do Rio de Janeiro, Rio de Janeiro, RJ, Brasil.

*Rua Elisa de Albuquerque, 157, B1.04/Apto.301 - Todos os Santos, Rio de Janeiro, RJ, Brasil.

CEP: 20770-290. E-mail: junimar.geoufv@ gmail.com

Artigo recebido em 03/01/2019 aprovado em 12/10/2019 publicado em 24/03/2020.

\section{RESUMO}

No presente artigo será apresentado o Estado da Arte das pesquisas em geografia escolar em educação em solos e processos erosivos, a partir da análise das produções brasileiras em forma de artigos, monografias, dissertações e teses, entre 2013 e 2017, verificadas no Portal de Periódicos CAPES, Scielo, ResearchGate, Google Scholar e os Anais do Simpósio Brasileiro de Educação em Solos (2014 e 2016). O objetivo é evidenciar os temas pesquisados sobre o ensino de geografia com abordagem em solos e processos erosivos nos anos finais do ensino fundamental e no ensino médio, bem como apresentar as instituições de ensino superior que incentivam este tipo de pesquisa no Brasil. Encontrou-se oito publicações que tratam sobre a temática, de oito instituições de ensino superior diferentes. Destacam-se em os seguintes temas: práticas de ensino e análise de materiais didáticos. Os trabalhos analisados trazem contribuições relevantes para o entendimento das necessidades e possibilidades das discussões de solos e processos erosivos na geografia escolar, apesar de evidenciarem que ainda são inúmeras as dificuldades enfrentadas pelos pesquisadores. Por fim, por ser uma atividade árdua e complexa, o Estado da Arte possui caráter crítico e reflexivo, auxiliando no desenvolvimento de novas demandas de pesquisa, conceitos e paradigmas.

Palavras-chave: Ensino de Geografia, Processos Erosivos, Estado da Arte.

\section{ABSTRACT}

This article will present the state of the art of research in school geography in soil education and erosion processes, from the analysis of Brazilian productions in the form of articles, monographs, dissertations and theses, between 2013 and 2017, verified in the Portal of CAPES Journals, Scielo, ResearchGate, Google Scholar and the Annals of the Brazilian Soil Education Symposium (2014 and 2016). The objective is to highlight the researched themes about the teaching of geography with approach in soils and erosive processes in the final years of elementary and high school, as well as to present the higher education institutions that encourage this type of research in Brazil. There were eight publications dealing with the subject matter of eight different higher education institutions. They stand out in the following subjects: practices of teaching and analysis of didactic materials. The analyzed works bring relevant contributions to the understanding of the needs and possibilities of the soil discussions and erosive processes in the school geography, although they show that the difficulties faced by the researchers are still numerous. Finally, because it is an arduous and complex activity, the State of Art has a critical and reflexive character, assisting in the development of new research demands, concepts and paradigms.

Keywords: Geography Teaching, Erosive Processes, State of the Art.

\section{RESUMEN}

En este artículo se presentará el Estado del Arte de las investigaciones en geografía escolar en educación en suelos y procesos erosivos, a partir del análisis de las producciones brasileñas en forma de artículos, monografías, disertaciones y tesis, entre 2013 y 2017, verificadas en el Portal de Periódicos CAPES, Scielo, ResearchGate, Google Scholar y los Anales del Simposio Brasileño de Educación en Suelos (2014 y 2016). El objetivo es evidenciar 
los temas investigados sobre la enseñanza de geografía con abordaje en suelos y procesos erosivos en los años finales de la enseñanza fundamental y en la enseñanza media, así como presentar las instituciones de enseñanza superior que incentivan este tipo de investigación en Brasil. Se han encontrado ocho publicaciones que tratan sobre la temática, de ocho instituciones de enseñanza superior diferentes. Se destacan en los siguientes temas: prácticas de enseñanza y análisis de materiales didácticos. Los trabajos analizados traen contribuciones relevantes para el entendimiento de las necesidades y posibilidades de las discusiones de suelos y procesos erosivos en la geografía escolar, a pesar de evidenciar que todavía son innumerables las dificultades enfrentadas por los investigadores. Por último, por ser una actividad ardua y compleja, el Estado del Arte posee carácter crítico y reflexivo, auxiliando en el desarrollo de nuevas demandas de investigación, conceptos y paradigmas.

Descriptores: Enseñanza de Geografía, Procesos Erosivos, Estado del Arte.

\section{INTRODUÇÃO}

O Estado da Arte é uma importante etapa de todo trabalho científico, uma vez que faz referência ao que já se tem pesquisado sobre o assunto pesquisado, evitando que se perca tempo com investigações desnecessárias e possibilidades de pesquisas inéditas. (MARQUES, 2004).

Neste contexto, aqui buscaremos o levantamento de produções científico-acadêmicas que levem a um panorama atual das pesquisas acerca das contribuições do ensino geografia para as discussões de solos e processos erosivos.

Entendemos que as questões ambientais, são hoje, objetos frequentes de discussão nas mais diversas áreas do conhecimento, já que todos os anos comunidades são afetadas por eventos de ordem climática, geológica, geomorfológica, que por muitas vezes são desencadeados/agravados pelas ações antrópicas. Desta forma, entender as dinâmicas do meio em que estamos inseridos faz-se indispensável para nos tornarmos cidadãos conscientes e capazes de atuar na conservação do meio ambiente.

Nesta seara, insere-se nossos objetos de investigação neste texto, as abordagens de solos e processos erosivos na geografia escolar brasileira, por entendermos que a escola possui grande responsabilidade na formação de cidadãos capazes de analisar e avaliar situações referentes aos processos naturais, sociais e a formação de áreas de riscos ambientais. E a geografia, a disciplina que ao se dedicar as abordagens dos fenômenos físico-naturais e sociais, se mostra como uma importante ferramenta capaz de possibilitar a interpretação de fenômenos sociais e naturais dispostos no espaço geográfico.

Nos currículos do Ensino Fundamental e Médio esse tema também está presente em outros componentes curriculares, tais como Ciências, Biologia e até mesmo História. Isso se deve à abrangência do tema, que compreende desde questões ligadas à própria pedologia (formação dos solos, classificação, fertilidade, conservação, mapeamento, entre outros) até aquelas mais gerais, decorrentes do papel do solo como interface (relevo, agricultura, hidrografia, clima, meio ambiente, economia e mesmo cultura).

Elenca-se aqui, como objeto de estudo, a erosão por se mostrar como um complexo problema ambiental, normalmente presente nas aulas de Geografia ou mesmo Ciências, com repercussões até sobre a economia.

Guerra (1994) coloca que as discussões sobre erosão dos solos devem ter a preocupação em incluir os elementos sociais, políticos e econômicos, nos estudos de degradação e conservação de solos, já que a atividade humana é um agente acelerador dos processos erosivos, transformando os ambientes, gerando e agravando os problemas ambientais atuais. Onde a erosão é entendida como o processo de desagregação e remoção de partículas do solo ou fragmentos de rocha pela ação combinada da 
gravidade com a água, vento, gelo ou organismos. Agindo continuamente sobre a superfície terrestre, a erosão é um dos principais agentes exógenos modeladores do relevo. (LEINZ E LEONARDOS, 1971)

Sendo assim, faz-se necessário entender o solo como um dos elementos que compõem o meio ambiente, e como tal, o conhecimento de suas características e peculiaridades tem imensa importância para o desenvolvimento de uma consciência ambiental pelo e para os estudantes. (SANTOS E ISAKA, 2015)

Em resumo, nossa pesquisa tem a característica essencialmente exploratória, com base em documentos de domínio público, "da literatura científica relativa ao objeto de estudo e cujo objetivo é a exploração da literatura procurando elaborar uma problemática teórica" (DE KETELE; ROEGIERS, 1996, p. 33, tradução nossa).

\section{MATERIAIS E MÉTODOS}

O solo é componente fundamental do meio ambiente, conhecer sua importância, características e serviços ecossistêmicos, contribui para a conscientização e sensibilização visando a sua sustentabilidade. Entretanto, no que tange o ensino no espaço escolar, os conhecimentos da ciência do solo possuem um pequeno espaço nas discussões na educação básica (LIMA; LIMA; MELO, 2007).

Entende-se que a geografia em seu vasto campo de atuação tem grande contribuição para as discussões dos solos e processos erosivos, uma vez que as questões ambientais estão intimamente ligadas ao objeto central do estudo da ciência geográfica, a relação sociedade e natureza e suas categorias de análise de paisagem, lugar e território, principalmente, sejam em escala local ou global.
Para o entendimento do espaço geográfico, objeto de estudo da Geografia, exige-se a necessária compreensão de que este é formado pela inter-relação entre sistemas de objetos naturais, culturais e técnicos e pelos sistemas de ações composta pelas relações sociais, culturais, políticas e econômicas (SANTOS 1996, apud PARANÁ, 2008).

No estudo do espaço geográfico o solo exerce papel importante na dinâmica da superfície terrestre, pois aparece como um corpo natural que apresenta a combinação de todos os outros fatores do ambiente, portanto os solos compõem os primeiros vestígios de uma região natural. Para "ler" estes vestígios, no entanto, devemos entender vários fatores, como geológicos, biológicos, físicos e químicos, que deram origem aos solos, principalmente as forças naturais e humanas que os modificam, as quais se configuram no espaço geográfico.

Como recurso natural dinâmico, o solo é passível de ser degradado em função do uso inadequado pelo homem, condição em que o desempenho de suas funções básicas fica severamente prejudicado, o que acarreta interferências negativas no equilíbrio ambiental, diminuindo drasticamente a qualidade vida nos ecossistemas, principalmente naqueles que sofrem mais diretamente a interferência humana como os sistemas agrícolas e urbanos.

O estudo científico do solo, a aquisição e disseminação de informações do papel que o mesmo exerce na natureza e sua importância na vida do homem, são condições primordiais para sua proteção e conservação, e uma garantia da manutenção de meio ambiente sadio e auto-sustentável.

A população em geral desconhece a importância do solo, o que contribui para ampliar processos que levam à sua alteração e degradação.

Neste contexto, verifica-se a importância de uma abordagem que alcance a população com o intuito de conscientização e não apenas como prevenção. A 
geografia escolar pode então, ser um instrumento indispensável para tal, buscando o entendimento da apropriação do espaço a partir do cotidiano e o lugar dos sujeitos.

Não se pode dissociar a realidade vivida no cotidiano do ensino realizado na escola. $\mathrm{O}$ aluno deve ser inserido nas questões pertinentes à sua realidade, pois, como sujeito de ação tem a capacidade de pensar e agir o/no espaço. Logo, se considera válido no tocante ao Ensino de Geografia a articulação realidade/aprendizagem ao abordar temas socioambientais que contemplem fenômenos geográficos do cotidiano.

Nesse sentido, buscando compreender de que modo o ensino de geografia tem tratado a temática dos processos erosivos, adotamos a metodologia do estado da arte, nos apoiando em Ferreira (2002) em seu artigo As pesquisas denominadas "Estado da Arte", no qual a autora define como pesquisas que:

(...) parecem trazer em comum o desafio de mapear e de discutir uma certa produção acadêmica em diferentes campos do conhecimento, tentando responder que aspectos e dimensões vêm sendo destacados e privilegiados em diferentes épocas e lugares, de que formas e em que condições têm sido produzidas certas dissertações de mestrado, teses de doutorado, publicações em periódicos e comunicações em anais de congressos e de seminários. Também são reconhecidas por realizarem uma metodologia de caráter inventariante e descritivo da produção acadêmica e científica sobre o tema que busca investigar, à luz de categorias e facetas que se caracterizam enquanto tais em cada trabalho e no conjunto deles, sob os quais o fenômeno passa a ser analisado. (FERREIRA, 2002, p. 258).

Para a seleção dos trabalhos adotamos como parâmetro o título e as palavras-chaves dos trabalhos, já que revistas, bancos de dados, mecanismos de busca e serviços de indexação classificam documentos usando palavras encontradas em seu título e resumo e em sua lista de palavras-chave para decidir se e quando exibir o seu artigo para leitores interessados.
A esse respeito, Miguéis et al. (2013) ressalta que:

O uso das palavras-chave potencia o acesso ao conteúdo dos documentos, para além da informação que é representada pelo título e resumo; traduz o pensamento dos autores, e mantém o contato com a realidade da prática quotidiana, acompanhando a evolução científica e tecnológica, que é refletida pelos documentos. (MIGUÉIS, 2013, p. 115)

As palavras-chave e o título possuem ligação direta com os temas centrais da investigação. A partir desses, o leitor deve ter uma noção do que irá encontrar no desenvolvimento da pesquisa. Em relação as palavras-chave, são normalmente utilizadas para permitir que o artigo seja posteriormente encontrado em sistemas eletrônicos de pesquisa. Por isso, deve escolher-se palavras-chave tão gerais e comuns quanto possível.

Lebrun (2007) coloca que o título é uma parte importante de qualquer pesquisa, já que deve chamar a atenção dos leitores potenciais, é a primeira introdução que leitores têm do trabalho e deve descrever o conteúdo do trabalho.

Visto isso, adotamos como orientação de busca, a $1^{\mathrm{a}}$ Lei de Zipf da Bibliometria que consiste na ocorrência de palavras no texto (BUFREM E PRATES, 2005). Deste modo, como filtro de busca consideramos os trabalhos nacionais escritos no idioma português. A busca e a seleção das publicações utilizaram a ocorrência dos descritores: erosão, processos erosivos, geografia, ensino de geografia, ensino de geomorfologia, ensino de geografia física, educação geográfica, prática de ensino, solos, educação em solos. Para a seleção dos trabalhos foi definido a necessidade da ocorrência de descritores que fizessem referências a ensino, geografia e processos erosivos. 
Foram consultados Portal de Periódicos CAPES/MEC, Scielo, ResearchGate, Google Scholar e os Anais do Simpósio Brasileiro de Educação em Solos - SBES (2014 e 2016) e selecionadas a publicações dos últimos cinco anos como recorte temporal possível para análise.

O recorte temporal implica o período de tempo relevante para a inteligibilidade do fato considerado. Assim, o recorte temporal deve estar também vinculado a esta ideia da pesquisa e não deve ser definido pela realidade em si, mas pela pergunta e pelo aspecto que a problemática quer revelar numa situação específica de pesquisa. (GIL, 2010; SILVA, SANTOS E DENIPOTI, 2011).

Estes 28 trabalhos foram lidos integralmente e analisados conforme o método de Análise de Conteúdo proposto por Bardin (2011). Para essa pesquisadora, esse método consiste em uma técnica metodológica que se pode aplicar em discursos diversos e a todas as formas de comunicação, seja qual for à natureza do seu suporte. Nessa análise, o pesquisador busca compreender as características, estruturas ou modelos que estão por trás dos fragmentos de mensagens tornados em consideração.

Estabeleceu-se como roteiro de leitura as orientações de Hanson e Mcnamme (2001), que colocam que a leitura científica analítica consiste em obter uma visão mais profunda sobre o tema de estudo, destacando os excertos mais significativos sobre as ideias do autor, considerando os motivos $\mathrm{e}$ as necessidades da leitura de determinado artigo ou estudo, antes de iniciar o processo de leitura como estratégia de pesquisa, considerando os seguintes passos: preparação, decidir o que ler, ler por largura, ler em profundidade e fazer anotações.

A análise dos trabalhos foi empreendida de acordo com o tema enfocado no estudo onde estabelecemos categorias de análise que indicassem os perfis das pesquisas, são eles: práticas de ensino e análise de materiais didáticos.

\section{RESULTADOS E DISCUSSÃO}

Ao realizar a leitura dos artigos verificamos a possibilidade de agruparmos por categorias de análise que favoreceram as discussões sobre as produções: práticas de ensino e análise de livros didáticos. A pesquisa buscou identificar e analisar a metodologia utilizada nas publicações e suas instituições de origem. Neste período foram publicados, oito trabalhos, conforme distribuição apresentada na Tabela 1 .

Tabela 1 - Distribuição dos trabalhos por instituições/categorias.

\begin{tabular}{c|l|l|c}
\hline Instituição & \multicolumn{1}{|c|}{ Trabalho } & Ano & Categoria \\
\hline UFTM & $\begin{array}{l}\text { Ferramentas lúdicas no ensino de solo: experiências com a } \\
\text { construção de um simulador de erosão em uma escola pública } \\
\text { do ensino fundamental }\end{array}$ & 2013 & $\begin{array}{c}\text { Prática de } \\
\text { ensino }\end{array}$ \\
\hline $\begin{array}{c}\text { UFSJ/Inpa/ } \\
\text { UFAM }\end{array}$ & Técnica de ensino de erosão em sala de aula & 2014 & $\begin{array}{c}\text { Prática de } \\
\text { ensino }\end{array}$ \\
\hline $\begin{array}{c}\text { Unesp } \\
\text { Rio Claro }\end{array}$ & $\begin{array}{l}\text { Adaptação e aplicação de experimento de erosão do solo em } \\
\text { Escola pública: reflexões didático-pedagógicas }\end{array}$ & 2016 & $\begin{array}{c}\text { Prática de } \\
\text { ensino }\end{array}$ \\
\hline
\end{tabular}




\begin{tabular}{c|l|l|c}
\hline UFF & $\begin{array}{l}\text { Aplicação de uma experimentoteca de solos: proposta de } \\
\text { educação ambiental para o ensino fundamental e médio }\end{array}$ & 2016 & $\begin{array}{c}\text { Prática de } \\
\text { ensino }\end{array}$ \\
\hline IFAM & Proposta didática para o ensino de solo na disciplina geografia & 2017 & $\begin{array}{c}\text { Prática de } \\
\text { ensino }\end{array}$ \\
\hline UFG & $\begin{array}{l}\text { Os riscos ambientais relacionados aos processos erosivos na } \\
\text { geografia escolar }\end{array}$ & 2017 & $\begin{array}{c}\text { Análise de } \\
\text { material } \\
\text { didático }\end{array}$ \\
\hline UFSM & $\begin{array}{l}\text { Educação em solos: uma experiência pedagógica com ênfase na } \\
\text { erosão hídrica do solo }\end{array}$ & 2017 & $\begin{array}{c}\text { Prática de } \\
\text { ensino }\end{array}$ \\
\hline IFPE & $\begin{array}{l}\text { Experimentoteca de solos: realização e reflexão de práticas } \\
\text { docentes por alunos do PIBID }\end{array}$ & 2017 & $\begin{array}{c}\text { Prática de } \\
\text { ensino }\end{array}$ \\
\hline
\end{tabular}

Organizado pelo autor.

Com base nessa tabela, podemos verificar que no período recortado não houve uma produção significativa dedicada ao ensino de geografia e processos erosivos, estando distribuídos em diferentes instituições pelo país. Entretanto, podemos visualizar uma tímida evolução dessas pesquisas (Figura 1), mas muito aquém do desejado, visto a importância e necessidade das discussões de solos e processos erosivos no espaço escolar.

Figura 1 - Relação de trabalhos publicados por ano (2013-2017)

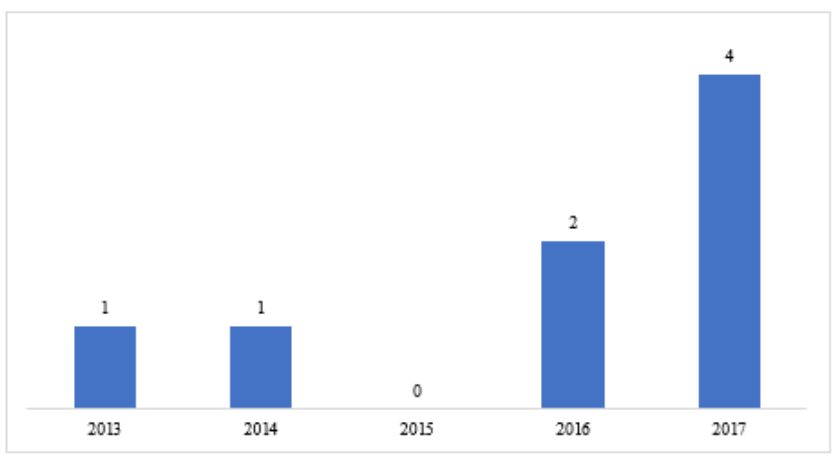

Organizado pelo autor.

Essa pequena produção, também pode ser reforçada quando quantificamos o número de trabalhos por base de dados nas quais este trabalho fez os levantamentos, se mostrando como um limitante para a realização da pesquisa (Figura 2).

Figura 2 - Relação de trabalhos por banco de dados (2013-2017)

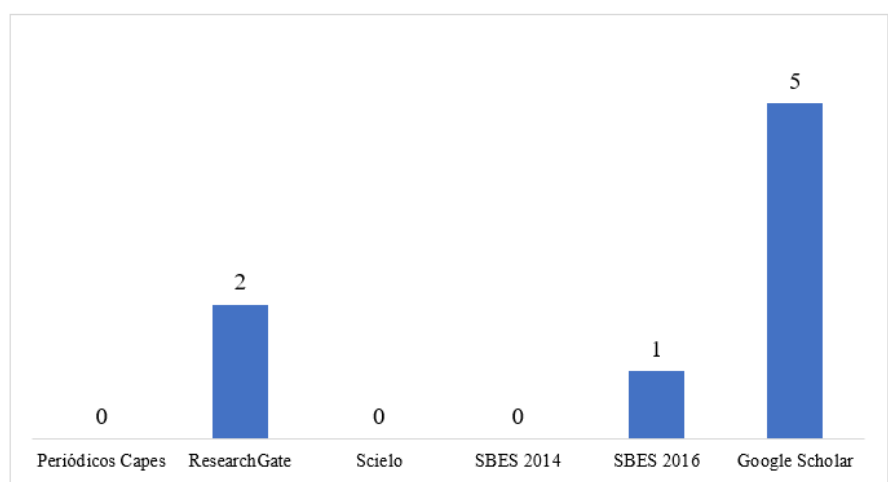

Organizado pelo autor.

As pesquisas que possuem como foco as práticas de ensino (sete publicações), apesar de contribuírem com a construção de novas formas de discussões dos processos erosivos no ensino de geografia apresentam metodologias repetitivas, sem traços de inovação metodológica. Consistem em apresentar práticas em que o os processos erosivos foram trabalhados através de experimentos e 
simuladores de erosão, porém sem uma aproximação dos alunos com o meio em que vivem.

Nessa categoria, se destaca um trabalho, que a partir da leitura, pode ser considerado mais completo e abrangente, intitulado Proposta didática para o ensino de solo na disciplina geografia, dissertação apresentada ao Mestrado Profissional em Ensino Tecnológico do Instituto Federal de Educação, Ciência e Tecnologia do Amazonas, Campus Manaus, em 2017.

Esta pesquisa buscou a elaboração de uma proposta didática para o ensino de solo na disciplina geografia, baseada na Teoria Geossistêmica, inutilizando de instrumentos de coletas de dados por questionários, roteiros norteadores levantamento bibliográfico, aulas expositivas, aulas de campo, experimentos no laboratório de Microscopia do IFAM.

A pesquisa supracitada possibilitou verificar que os livros didáticos possuem erros conceituais graves e desatualizados que são reproduzidos pelos professores sem uma visão crítica em aulas expositivas com metodologia engessada. Os levantamentos feitos proporcionaram a produção de um guia didático para uso dos alunos, denominado A origem, formação e erosão do solo: uma proposta para no processo de ensino- aprendizagem.

Na publicação que utiliza como instrumento metodológico a análise de material didático (uma publicação), o objetivo central versou sobre a ocorrência e abordagem dos processos erosivos associados aos riscos naturais e ambientais nos livros didáticos de geografia e prática docente na educação pública. Os autores afirmam que o tema não se configura como um dos temas centrais das práticas docentes e dos materiais didáticos e que quando abordado, encontra-se próximo à perspectiva dos impactos ambientais.

Além disso, verifica-se que no ensino dos conteúdos relativos aos processos erosivos utiliza-se como escala de análise, predominantemente, a área rural, dificultando a compreensão dos estudantes acerca desses processos em áreas urbanas, espaço de vivência da maioria deles.

O foco de nossas análises, neste estudo se dirige à metodologia utilizada pelos pesquisadores, onde evidenciamos a pouca relevância dada à discussão teórica. Os procedimentos de coleta de dados mais utilizados foram observação, análise documental e experimentos/simuladores, estratégias que já bastante utilizadas no meio acadêmico. Há pesquisas em que foi utilizada a combinação de um ou mais destes procedimentos,

Entretanto, o que se verifica é que não houve preocupação em explicar as opções metodológicas feitas em função do referencial teórico-metodológico adotado. No entanto, os pesquisadores nem sempre trazem na discussão dos resultados o que desenvolveram no capítulo destinado à revisão de literatura.

Sendo assim, cabe ressaltar a timidez das pesquisas realizadas sobre ensino de geografia e processos erosivos nos últimos cinco anos, o que parece indicar certa dificuldade de inserção e atenção ao tema nas instituições de ensino superior brasileiras o que possivelmente é o responsável pela similaridade dos trabalhos.

Verificou-se, também, que os únicos temas abordados pelos pesquisadores no período são práticas de ensino e análise de materiais didáticos, respectivamente, o que é decorrente das discussões que tem sido feitas à reboque das reformas e das políticas educacionais das duas últimas décadas que geraram mudanças na organização e divisão do trabalho docente, nos vários níveis de ensino e modalidades de ensino, na formação inicial e continuada de professores com vistas à melhorias na qualidade da educação. 


\section{CONCLUSÃO}

Os trabalhos analisados neste estudo trazem contribuições relevantes para o entendimento das necessidades e possibilidades das discussões dos processos erosivos na geografia escolar, apesar das análises dos oito trabalhos evidenciarem que ainda são inúmeras as dificuldades enfrentadas pelos pesquisadores.

A partir dos trabalhos analisados podemos inferir que o tema carece fortemente de discussões na academia, se mostrando como um rico campo de estudos que merece atenção por parte das instituições de ensino superior, dada a importância dos solos para a existência humana,

É necessário ressaltar a importância da utilização de técnicas para o ensino de geomorfologia em sala de aula, sobretudo, o ensino de erosão que muitas vezes desperta a curiosidade do aluno, e assim, amplie a percepção do solo como componente essencial do meio natural e humano, já que é sobre os solos que as sociedades estabelecem suas relações suas moradias, retiram seus alimentos, trabalham e travam suas lutas, além de ser por ele que passa boa parte dos resíduos advindos das atividades humanas.

Estudos sobre articulação entre geografia, ensino e processos erosivos são valiosos no campo da educação, pois pode se tornar um importante aliado para os alunos compreenderem o seu lugar vivido, buscando aproximar a teoria com a realidade/fenômenos dentro o contexto que estão inseridos, uma vez que o Brasil possui características naturais e de ocupação urbana que favorecem a ocorrência de desastres naturais, além de um poder público ineficiente.

Recursos e materiais didáticos podem ser utilizados em sala de aula como suportes, auxílios, momentos práticos e lúdicos que propiciam uma abordagem ampla entre teoria e prática, buscando significados e exemplos que podem complementar e facilitar o entendimento dos conteúdos mais diversos.

Os conteúdos pedológicos são extremamente importantes para a conscientização ambiental da sociedade não só no que diz respeito à educação bancária (formal), mas também no âmbito informal, permitindo que a sociedade como um todo perceba e possa modificar os impactos sobre o solo, seja por suas ações individuais ou coletivas.

Quando o tema processos erosivos é enfocado, encontra-se mais próximo à perspectiva dos impactos ambientais. Comumente as abordagens reforçam um ideário midiático e de senso comum que culpabiliza a sociedade pelos problemas ambientais que caracterizam o quadro de degradação ambiental instaurado na atualidade, sem inserir nesse quadro a compreensão em torno dos condicionantes físico-naturais, inerentes a esses processos.

Esses aspectos evidenciam a importância de uma sólida formação inicial e continuada desses profissionais no sentido de favorecer o trabalho com essa temática na Educação Básica, contribuindo, consequentemente, para a formação cidadã dos alunos.

A temática sobre a educação ambiental, tem se tornado cada vez mais debatido em muitas conferências, tendo como ponto de partida a legislação e conforme exposto na constituição de 1988, observa se a grande preocupação em torno da conservação do meio ambiente, sendo proposto em inúmeras conferências alternativas sobre sua conservação. Estas propostas visam, para além da educação ambiental pautada nos deveres da sociedade, que existam políticas sociais também 
nos espaços das escolas a fim de que a educação ambiental se estabeleça como uma política educacional comprometida no processo educativo da sociedade. Isto reforça o quão primordial são os cuidados necessários com o solo, tal como já mencionado em vários momentos como parte importantíssima da dinâmica do meio ambiente.

Por essas e muitas outras questões de ordem ambiental e sua degradação que se faz necessário estudo o estudo do solo, não como elemento isolado, mas como parte integrante no meio ambiente sendo correlacionado.

Para que se tenha a construção do conhecimento dos solos, é necessário que se tenha conhecimento de sua concepção, sua morfologia, para que assim, possa se avançar com mais propriedade acerca de sua importância para a vida da sociedade.

Desta forma, é indispensável a inclusão de crianças e adolescentes em atividades de prevenção, já que esta parcela da população encontra-se em momento adequado para aprender e refletir sobre os temas que lhe são propostos, além de multiplicar este conteúdo no seu meio de convívio.

A geografia acadêmica pode proporcionar contributos importantes de forma a alcançar os objetivos da conservação ambiental, já que em entre seus objetos de estudo, está a preocupação em compreender a ação do homem sobre a natureza, produzindo o seu meio de vivência e a sua transformação.

Destacamos a importância dessa aproximação para que nossos alunos possam compreender o porquê dos fenômenos ocorrerem, qual o motivo deles estarem acontecendo naquela localidade, e formas de tentar minimizar os impactos e formas de atuação no caso de um evento.
Recursos e materiais didáticos podem ser utilizados em sala de aula como suportes, auxílios, momentos práticos e lúdicos que propiciam uma abordagem ampla entre teoria e prática, buscando significados e exemplos que podem complementar e facilitar o entendimento dos conteúdos mais diversos.

Todos os autores declararam não haver qualquer potencial conflito de interesses referente a este artigo.

\section{REFERÊNCIAS}

BARDIN, L. Análise de conteúdo. São Paulo: Edições 70. 2011.

BARROS, M. A. M. Recursos multisensoriais no ensino superior. In: Anais do XXX Congresso Brasileiro de Ciência do Solo, Recife, PE, Sociedade Brasileira de Ciência do Solo. CDROM. 2005.

BECK, U. Sociedade de risco: rumo a uma outra modernidade. Tradução de Sebastião Nascimento. São Paulo: Ed. 34, 2010. 368 p.

BELÉM, R. P. Analise das abordagens e discussões do conteúdo de pedologia nos livros didáticos de geografia. Dissertação de Mestrado. Universidade Federal Rural do Rio de Janeiro. Rio de Janeiro, 2010. Disponível em:

$<$ http://www.ia.ufrrj.br/ppgea/resumo/Roberta\%20 Prates\%20Belem.htm>. Acesso em: 01 ago. 2015.

BUFREM, L. S.; PRATES, Y. O saber científico registrado e as práticas de mensuração da informação. Ciência da Informação, v. 34, n. 2, p. 9-25, 2005. Disponível em: < http://revista.ibict.br/ciinf/article/view/1086/1190> . Acesso em: 06 jun. 2018.

DE KETELE, J. M.; ROEGIERS, X.

Méthodologie du recueil d'informations: Fondements dês méthodes d'observations, de questionnaires, $d$ 'interviews et d'études de documents, Bruxelles, De Boeck Université, 1996, 3 ème édition.

FERREIRA, N. S. A. As pesquisas denominadas "estado da arte". Rev. Educação \& Sociedade., v. 23, n. 79, p. 257-272. 2002. Disponível em: $<$ http://www.scielo.br/scielo.php?script=sci_arttext 
\&pid $=$ S0101-

$73302002000300013 \& \ln \mathrm{g}=\mathrm{pt} \& \ln \mathrm{g}=\mathrm{pt}>$. Acesso em: 08 abr. 2018.

GIL, A. C. Como elaborar projetos de pesquisa. 5. ed. São Paulo: Atlas, 2010.

GUERRA, A. J. T. A erosão de solos no contexto social. Anuário do Instituto de Geociências da Universidade Federal do Rio de Janeiro, Rio de Janeiro, v. 17, p. 14-23, 1994. Disponível em: < https://www.researchgate.net/profile/Antonio Gue rra3/publication/26431746_A_Erosao_dos_Solos no_Contexto_Social/links/00b7d5142efed73aef00 0000/A-Erosao-dos-Solos-no-Contexto-

Social.pdf>. Acesso em: 03 jul. 2018

HANSON, M.; MCNAMME, D. Leitura eficiente de artigos científicos. Tradução de Renata Fortes. São Carlos: ICMC - USP São Carlos, 2001.

Disponível em:

<http://www.icmc.usp.br/ renata/Leitura4.PDF>. Acesso em: 15 jun. 2018.

LEBRUN, J-L. Scientific writing: A reader and writer's guide. Boston, MA: World Scientific, 2007.

LEINZ, V.; LEONARDOS, O. H. Glossário geológico: com a correspondente terminologia em inglês, alemão e francês. São Paulo: Nacional, 1971. $236 \mathrm{p}$.

MIGUÉIS et al. A importância das palavraschave dos artigos científicos da área das Ciências Farmacêuticas, depositados no estudo geral: estudo comparativo com os termos atribuídos na MEDLINE. Rev. de Ciência da Informação e Documentação, Ribeirão Preto, v.4, n.2, Ed. esp., p.112-125, jul./dez. 2013. Disponível em:

$<$ http://www.revistas.usp.br/incid/article/view/692 84/71742>. Acesso em: 18 jun. 2018.

SANTOS, J. A. A. Saberes em solo em livros didáticos da educação básica. Dissertação de Mestrado. Universidade Federal de Viçosa, Viçosa, 2011. Disponível em: <http://www.locus.ufv.br/bitstream/handle/123456 789/5496/texto\%20completo.pdf?sequence=1\&isA llowed=y >. Acesso em: 07 jul. 2018.

SANTOS, E, F.; ISAKA, S. R. A maquete como recurso didático no ensino de solos. Rev.
Perspectiva Geográfica, Marechal Cândido Rondon, v. 10, n. 12, 2015. Disponível em: < http://e-

revista.unioeste.br/index.php/pgeografica/article/vi ew/14129>. Acesso em: 18 jul. 2018.

SILVA, E. A.; SANTOS, F. L.; DENIPOTI, C. Métodos e Técnicas de Pesquisa em História II. Ponta Grossa: UEPG/NUTEAD, 2011. 110p.

Disponível em:

<http://www.cesadufs.com.br/ORBI/public/upload Catalago/13550906102014Metodologia da Pesqui sa_Historica_Aula_1.pdf $>$. Acesso em: 16 jun. 2018. 